\title{
Editorial
}

\section{Paz: una construcción colectiva en medio de la crisis social del Covid-19}

\author{
Jairo Andrés Hernández Cubides
}

La primera mitad del año 2020 representó un nuevo reto para todo el mundo, de cara a la actual pandemia ocasionada por el virus Sars-CoV-2 (en inglés, Severe Acute Respiratory Syndrome Coronavirus 2) causante de la enfermedad Covid-19. El mundo entero se vio progresivamente replegado y empujado contra las cuerdas por esta nueva crisis sanitaria que avanzó a paso firme por el globo, desde que a finales del año 2019 se anunciara la epidemia en Wuhan, ciudad de China. Así, tanto Colombia, en mitad del gobierno del Presidente Iván Duque Márquez, como Bogotá con la recién elegida alcaldesa Claudia López, se prepararon fervientemente para la inminente llegada del virus al país.

De esta manera, el día 6 de marzo el Ministerio de Salud y Protección Social anunció el primer caso de la enfermedad presente en el país: una mujer de diecinueve años que provino de Italia en un vuelo internacional. No pasó mucho tiempo para que Colombia, en medio del asombro de una población incrédula ante una situación tan atípica, empezara a adoptar las medidas que otros países habían tenido que asumir meses atrás.

El 12 de marzo, por orden presidencial, se cancelaron y aplazaron todos los eventos públicos hasta el 30 de mayo, lo que incluyó, por ejemplo, el Festival Internacional de Cine de Cartagena de Indias y la Feria del Libro de Bogotá; el 15 de marzo se suspendieron las clases presenciales en todos los colegios públicos y privados del país y, un día después, se anunció el cierre de todas las fronteras terrestres, marítimas y fluviales, además se prohibió el ingreso y la salida de cualquier ciudadano colombiano o extranjero del país; finalmente, el 20 de marzo se declaró cuarentena total en Colombia. Una medida que en principio se enunció duraría diecinueve días, pero que resultó en más de cinco meses de aislamiento estricto, aunque a lo largo de este periodo se fueron incluyendo cada vez más excepciones con el propósito de cuidar la economía y preparar la reactivación del país.

Las calles de Colombia se vieron desiertas súbitamente y todos los ciudadanos asaltaron las estanterías de los mercados, llevándose a sus hogares grandes cantidades de productos y alimentos, impulsados por el miedo de quedarse sin recursos en mitad del encierro; los niños, niñas y jóvenes de colegios y universidades, se vieron en la obligación de apartarse de sus compañeros de estudio y empezar a recibir clases de manera virtual; el comercio presencial, el de toda la vida, cayó en picada y las pérdidas no hicieron más crecer; y un constante e ineludible temor se apoderó de todas las decisiones y actuares de los habitantes del país: aplanar la curva y cuidar a los ancianos y la población de riesgo se convirtieron en las frases más sonadas por meses.

Las repercusiones de la crisis sanitaria para los colombianos no serán pocas, así lo han estado advirtiendo los expertos en salud y economía a lo largo de este periodo. En materia de salud, el sedentarismo debido a la cuarentena prolongada, y los problemas físicos que este puede ocasionar, se presentan como elementos importantes a considerar en el futuro del país. Sin embargo, la salud mental de los colombianos es el factor del que más se ha hablado últimamente: el encierro y el distanciamiento social, acompañados del estrés por una economía que no parece tener un horizonte de recuperación, representan graves peligros al equilibrio mental de la población nacional, la depresión y la ansiedad se tornan parte del cotidiano, mientras la idea mesiánica del descubrimiento de la vacuna se instala como la única esperanza para el retorno a la normalidad. 
Sin duda, la pandemia ha dejado al descubierto grandes cuestiones irresolutas de Colombia en materia social. Ejemplos de esto pueden ser, la pobre cobertura de salud, especialmente de unidades de cuidados intensivos (UCI), con la que el país comenzó a hacerle frente al virus; las precarias condiciones laborales del personal de salud que se asomaron a la esfera pública con la crisis; la precariedad social cristalizada en los pañuelos rojos colocados en las ventanas de los hogares que se fueron quedando sin alimentos en medio de la cuarentena; o la ausencia de empatía manifiesta en las constantes actitudes de rechazo a los médicos, enfermeros y personal de los centros de salud y hospitales del país.

No obstante, la crisis también ha representado un escenario para el florecimiento de espacios de ayuda comunitaria y conciencia. Sin dejar de mencionar, por supuesto, algunas de las iniciativas gubernamentales que buscaron ofrecer comida y subsidios a las familias más necesitadas, se empezaron a observar proyectos ciudadanos para la ayuda a los más desfavorecidos. El lema, anunciado por Claudia López en medio de la lucha contra el virus: este es momento para ayudar, se posó en los actuares de muchos de los habitantes del país, y se manifestó en constantes noticias acerca de figuras empresariales que antepusieron las necesidades de sus empleados al cuidado del capital privado.

Pareció entonces que el sol asomaba en Colombia ocasionalmente, o que brindaba una leve calidez a pesar del escenario lúgubre y desesperanzador que el miedo al contagio grabo en la cotidianidad nacional. Pareció que todos los problemas del país se focalizaron en un solo gigante a derrotar y que la unión de todos como nación podría significar una inexorable victoria. No obstante, los problemas que siempre han aquejado a Colombia no hicieron sino tomar un respiro al inicio de la crisis sanitaria: la violencia, la corrupción y la guerra no pararon con el aislamiento preventivo (nombre de la cuarentena en el país).

A la espera de la llegada del virus, a tan sólo cinco días de comenzar el año, en Bojayá (Chocó) se reportó la incursión de 300 hombres pertenecientes a las Autodefensas Unidas de Colombia, y en Tibú se notificó de la masacre de tres personas que se atribuyó al inicio de una disputa territorial entre el grupo guerrillero ELN y Los Rastrojos, una noticia que significaría el inicio de una constante lista de hechos violentos a lo largo del transcurso del año. Para el mes de mayo, las masacres, los atentados y los hechos de corrupción se convirtieron en titulares constantes en los noticieros nacionales, siempre acompañando los informes diarios acerca del número de contagios, muertos y recuperados del Sars-CoV-19.

Como se mencionó al inicio de esta nota editorial, el fuerte panorama sanitario ha penetrado las fronteras de la mayoría de los países del globo y de esta manera ha complicado la cotidianidad mundial, que de por sí ya era inestable al final del año 2019; una situación que, como se podría esperar, agravó muchos de los fenómenos y condiciones ya presentes en Colombia. La economía se ha visto fuertemente afectada, el trabajo ha disminuido drásticamente y las oportunidades se tornan cada vez más esquivas. El 2020 ha sido un periodo repleto de pruebas, desafíos, derrotas y pequeñas victorias que han amenizado el lento pasar de los meses.

\section{¿Qué ofrece la edición 13.1 de la revista Ciudad Paz-ando?}

El presente se ha inundado de cuestiones por analizar, estudiar, teorizar y, sobre todo, problematizar; en este sentido, la academia no es indiferente a la convulsión e inestabilidad actual y, aunque el panorama nacional sigue opacado por bruma lúgubre y opaca las perspectivas sobre el futuro, florecen en la comunidad científica buscando ofrecer algunas apreciaciones sobre los retos y oportunidades que ya estaban presentes y para los que han nacido en un momento tan peculiar como el año curso. En consecuencia, volviendo sobre los pasos del país en los últimos meses, es importante que, a pesar de las circunstancias sanitarias en donde parece converger toda la atención de la comunidad nacional, no se deje de reflexionar acerca de la construcción de la paz del país; un proceso que todos los días enfrenta nuevos riesgos, retos y particularidades que, desde la academia, se buscan hacer visibles para facilitar la articulación nacional y finalmente su consecución. 
El primer artículo del dossier central de este número de la revista Ciudad Paz-ando volumen 13 número 1, autoría de Andrea Arévalo y Edwin Figueroa, invitan a analizar cuáles son las conexiones entre la ideología de las guerrillas y los grupos paramilitares, y los modelos de gobernanza rebelde que estos actores armados han consolidado en territorios asegurados en Colombia, incluyendo en el estudio elementos como los intereses que ejercen los actores armados sobre el control territorial, la legitimidad de la población civil hacia la gobernanza rebelde consolidada y la relación entre actores armados y la población.

A renglón seguido, Cristina Álvarez presenta un artículo de reflexión acerca de la dimensión política de las familias colombianas en el contexto del conflicto armado, planteando vínculos entre lo público y lo privado como escenarios que confluyen y que enmarcan asuntos como la familia, sus configuraciones y prácticas como elementos de carácter político. Un análisis que supera la lógica tradicional del estudio poblacional y entiende tales fenómenos como construcciones sociales que demarcan los tránsitos de los habitantes del territorio nacional en su resistencia contra la guerra.

En un segundo momento, Lida Osorio, Víctor Molina, Arnulfo Hurtad y Cristian Valencia, comparten su estudio sobre la presencia de las categorías de paz y salud en los trabajos de grado del proyecto profesional en Educación física de la Universidad de Antioquia, sugiriendo que tales conceptos son de vital importancia para la transición nacional a la paz, en tanto demarcan un derrotero cotidiano saludable y orgánico a la convivencia pacífica de las comunidades. Seguidamente, Luz Stella Fuentes analiza la relación que existe entre la convivencia escolar, la corresponsabilidad social y la construcción de paz, en un estudio de caso que involucra la labor docente y el diario vivir en una institución de educación secundaria en el país.

Acto seguido, son dos los artículos que concluyen el dossier central de este número. En primer lugar, Bárbara Silva realiza una reflexión crítica a la Reserva Campesina de Cabrera (Cundinamarca), haciendo uso de la experiencia de la cartografía social, con el objetivo de contribuir a la discusión sobre el reconocimiento político de campesinos, abordando cuestiones como las carencias históricas a nivel jurídico, la violencia sistemática, la pobreza, y la pérdida de identidad cultural y tradicional campesina en Colombia. En segundo lugar, Jannis Rubiano, David Torres y Guillermo Carrillo, ofrecen un estudio de caso, devenido de la aplicación de un modelo de educación basado en las pedagogías de la memoria, que propende por evidenciar los elementos más relevantes que hacen necesaria la enseñanza de la historia reciente para la transición actual de Colombia a la paz.

En la sección intermedia de este número, llamada Pensando regiones, Laity Velásquez y Luisa María Bernal presentan un análisis sobre la atención a las víctimas de desplazamiento forzado en el municipio de Cajicá (Cundinamarca), en una discusión que se centra en determinar si en verdad se ha estado implementado un enfoque diferencial en la atención a esta población en el marco de la reparación a las víctimas estipulada en la Ley 1448 de 2011.

A continuación, en el apartado denominado Voces otras, se presenta el artículo elaborado por Juan David Cabrera, quien realiza un seguimiento exhaustivo a los planteamientos de Hegel respecto al reconocimiento que deviene en un horizonte de intersubjetividad, evidenciando su relación con la política agonista que propone Chantal Mouffe. Esto último, con el objetivo de entablar un diálogo entre la concepción de poder de Mouffe y la intersubjetividad hegeliana que media las relaciones entre el Estado y el pueblo.

En la una última sección, este número comparte la reseña del libro titulado Reparación simbólica: jurisprudencia, cantos y tejidos, primer volumen de la serie "Estudios sobre la Reparación Simbólica”, adelantado por la línea de Derechos Culturales: Derecho, Arte y Cultura, perteneciente al Departamento de Derecho Constitucional de la Universidad Externado de Colombia. Ejemplar que contó con la edición de Yolanda Sierra León, la coordinación editorial de Manuel Alejandro Albarracín Pinzón y una cubierta que se nutre de las fotografías "Vajilla de Camacho" de la serie “¿De qué sirve una taza?" de los fotógrafos Juan Manuel Echavarría y Fernando Grisales. Un manuscrito que, en 343 páginas, presenta 
diferentes estudios acerca de la asertividad y pertinencia de los procesos de reparación simbólica llevados a cabo por el Estado y algunas organizaciones particulares a lo largo de los últimos años en el territorio nacional.

Finalmente, cerrando este interesante número, Jairo Andrés Hernández Cubides y Jefferson Arley Díaz invitan al público lector a sumergirse en una interesante y aclaradora entrevista realizada a José Antequera Guzmán, hoy director del Centro de Memoria, Paz y Reconciliación. Un diálogo que reflexiona sobre las dificultades, retos y oportunidades que se extienden en el derrotero de la construcción de memoria histórica en Colombia y que también indaga sobre la vida y pensamientos de un líder nacional en esta labor; un trabajo que se sitúa como uno de los más relevantes en el marco de la transición del país a la paz.

Jairo AndRÉs Hernández Cubides

EDITOR

Revista CiUdad Paz-ANDO 